\title{
Effect of Ethephon on the Liver in Albino Rats: A Histomorphometric Study
}

\author{
Pooja Bhadoria $^{1}$, Mahindra Nagar ${ }^{2}$, Veena Bahrioke ${ }^{2}$, Ajeet Singh Bhadoria ${ }^{3}$
}

Background: Chemicals that are commonly used for artificial ripening and to increase the shelf life of fruits and vegetables are ethylene, ethane, calcium carbide, and ethephon. The present study was conducted to study the effect of ethephon on the morphometry of rat liver.

Methods: Ethephon was administered by oral gavage tube to 10 adult Wistar albino rats at a dose of $200 \mathrm{mg} / \mathrm{kg}$ body weight/day for 14 days. Ten controls were maintained. The animals were sacrificed within $24 \mathrm{~h}$ of administering the last dose by perfusion with formal saline under anesthesia. Liver was dissected and processed for paraffin embedding. Histomorphometric studies were done on randomly selected sections of the liver and the data obtained were tabulated and statistically analyzed.

Results: In the experimental rats, the hepatocytes had a mean long and short diameter of $15.02 \pm 4.20$ and $12.08 \pm 3.02 \mu \mathrm{m}$, respectively. In the control animals, the mean long and short diameters were found to be $16.5 \pm 3.59$ and $13.9 \pm 3.59 \mu \mathrm{m}$, respectively. The nucleus of the hepatocytes had a mean long and short diameter of $5.08 \pm 1.93$ and $5.08 \pm 1.93 \mu \mathrm{m}$, respectively, in the ethephon-treated rats and $6.15 \pm 1.72$ and $6.05 \pm 1.68 \mu \mathrm{m}$, respectively, in the control animals. The decrease in diameters of the hepatocytes and their nuclei was statistically significant. At some sites, the parenchyma showed pyknotic nucleus and inflammatory infiltrations. There was a statistically

\section{At a Glance Commentary \\ Scientific background of the subject}

We consume fruits and vegetables as they are "immune boosters," antioxidants, and have anti-aging properties. However, the question arises whether these fruits and vegetables available are really safe for our consumption. These days, the use of plant growth regulators is on rise to meet the increasing demand of the community, due to which these "immune boosters" are becoming toxic.

\section{What this study adds to the field}

The present study documents that ethephon, which is a commonly used plant growth regulator, causes inflammatory and degenerative changes in the liver and should be cautiously used. It suggests that further research is required to know the quantity of ethephon present in and on the ethephon-ripened fruits and vegetables and to find what can be done at the level of policymakers and consumers to avoid its toxicity. significant increase in the diameters of the central vein and sinusoids. Dilatation of the bile canaliculi was seen in between the hepatocytes.

Conclusion: The plant growth regulator, insecticide, and fruit ripener, ethephon, caused inflammatory and degenerative changes in the liver with associated cholestasis, probably suggestive of toxic hepatitis. (Biomed J 2015;38:421-427)

\section{Key words: ethephon, hepatotoxicity, organophosphorus}

$I^{t}$ $\mathrm{t}$ is well known that nowadays chemicals are being used for artificial ripening. The commonly used ones are ethylene, ethane, calcium carbide, and ethephon. Excessive use of these chemicals would certainly be associated with many health hazards. The United States Environmental Protection Agency (1998) stated that plant growth regula-

From the ${ }^{1}$ Department of Anatomy, Maulana Azad Medical College, New Delhi, India; ${ }^{2}$ Department of Anatomy, University College of Medical Sciences, New Delhi, India; ${ }^{3}$ Department of Clinical Research, Institute of Liver and Biliary Sciences, New Delhi, India Received: Jul. 19, 2014; Accepted: Mar. 04, 2015

Correspondence to: Dr. Ajeet Singh Bhadoria, Department of Clinical Research, Institute of Liver and Biliary Sciences, India. Room No. 1043, D-1, Vasant Kunj, New Delhi - 110 070, India. Tel.: 91-11-46300000; Fax: 91-11-46300010; E-mail: ajeetsinghbhadoria@gmail.com

DOI: $10.4103 / 2319-4170.155589$ 
tors should be used at suitable times and quantities as prescribed, if required. ${ }^{[1]}$ Ethephon is one of the most widely used plant growth regulators because of its broad-spectrum activities. It is used as a fruit ripener, promotes flower induction, fruit coloration, and fruit abscission. ${ }^{[2-4]}$ It is currently being used to promote pre-harvest ripening of fruits, vegetables, and cereals. In India, it is being extensively used to accelerate post-harvest ripening of bananas. ${ }^{[5]}$ Unlike the other four classes of plant hormones, ethylene is a gas at room temperature and diffuses easily through the air from one plant to another. The saying "One bad apple spoils the barrel" has its basis in the effects of ethylene gas. One rotting apple will produce ethylene gas, which stimulates the nearby apples to ripen and eventually spoil because of over-ripening.

When administered orally, it causes gastroenteritis, respiratory diseases, and necrotic hepatitis in rats and mice. The teratogenic effects in rats were folded retina, microopthalmia, and absent tail. ${ }^{[6]}$ Other effects observed in rats are significant increase in pancreatic islet cell tumors, ${ }^{[7]}$ decrease in urinary $\mathrm{pH}$ and thyroid weight with an increase in thyroglossal duct cysts, increased mammary gland ectasia, ovary stromal cell hyperplasia, increased kidney weight, glomerulosclerosis, nephritis, increased biliary hyperplasia, liver cholangiofibrosis and increased incidence of loose stools, ${ }^{[8]}$ small thymuses and necrosis in the stomach, ${ }^{[9]}$ mineralization of brain, fibrosis of heart, thymic lymphosarcomas, ${ }^{[10]}$ and glomerulonephritis in the kidneys. Plant growth promoters have been found to be harmful to the kidney, brain, and liver in experimental rats. ${ }^{[11]}$ These agents can have direct and indirect cholinergic effects on intestinal muscle contraction. ${ }^{[12]}$

Clinical signs in terms of hypothermia, prostration, ataxia, salivation, tremors, severe dermal irritation, dyspnea, erythema, desquamation, skin fissuring, edema, histological acanthosis, and chronic active inflammation of treated skin have been reported ${ }^{[13]}$ Lumbar spinal cord hemorrhage, kidney lesions (mineralization and tubular regeneration), and benign cutaneous lesions at high dose levels have been reported.$^{[14]}$ Necrotic thickening of the walls of stomach and duodenum has been observed. In the stomach and small intestine, smooth muscle hypertrophy has been reported. ${ }^{[15]}$ It is known to cause mutagenic, teratogenic, biochemical alterations and increase in all types of structural chromosomal aberrations in mice. ${ }^{[16]}$ The resorption rates have been found to increase and fetal viability has been found to decrease when given to artificially inseminated rabbits. ${ }^{[17]}$ It was found to suppress the spontaneous development of lung tumors in a mice strain. ${ }^{[18]}$

The present study was conducted to assess how safe is this widely used ethephon which we are unknowingly consuming daily. As liver is the organ where most of the substances undergo their first-pass metabolism, it will be the site most probably affected by ethephon metabolism. Despite the known toxicities with ethephon exposure, there is a dearth of literature on the histopathological effects on the liver. Hence, the present study has been conducted to evaluate the histomorphometric changes in the liver following administration of ethephon in a mammal, the albino rat.

\section{METHODS}

Inbred adult Wistar albino rats weighing 150-200 g were used for the study. The rats were procured from the animal house of University College of Medical Sciences (UCMS) and Guru Tegh Bahadur Hospital, Delhi. The animals were divided into two groups, experimental and control groups, containing 10 animals each.

The animals were group housed ( $12 \mathrm{~h} \mathrm{light/dark} \mathrm{cycle)}$ with ad libitum access to food and water. The body weights were recorded before the onset of the experiment and on day 7 and day 14 of the experiment. The animals of Group I were given ethephon at a dose of $200 \mathrm{mg} / \mathrm{kg}$ body weight/ day for 14 days by oral gavage during the morning hours. According to the International Programme on Chemical Safety, 2002, the least observable adverse effects in rats were seen at a dose of $200 \mathrm{mg} / \mathrm{kg} /$ day for ethephon and a decrease in liver/body weight ratio was also observed. ${ }^{[19]}$ In the study of Berouty et al., neurotoxic effects of ethephon were observed after the administration of ethephon to rats for 14 days by oral gavage tube and a decrease in body weight was documented. ${ }^{[20]}$ Therefore, we assumed that the possible accompanying hepatotoxic changes are highly amenable at 14 days. So, we decided to give the dose of $200 \mathrm{mg} / \mathrm{kg} /$ day for 14 days. In Group II, the gavage tube was introduced for 14 days at the same time and these rats served as controls. The animals of both groups were sacrificed within $24 \mathrm{~h}$ of the last dose by perfusion with formal saline under anesthesia.

\section{Perfusion of animals}

The animals were anesthetized by keeping them in an inverted glass jar containing a large piece of cotton soaked in anesthetic ether. Anesthesia was achieved in 5-10 min. The anesthetized rats were pinned up on the dissection board and a midline incision was made on the skin extending from the xiphoid process to the jugular notch. Sternum was lifted by cutting the ribs along its sides. The heart and the ascending aorta were exposed by removing the overlying fat and thymus. A ligature was passed under the ascending aorta and a small nick was made in the left ventricle through which a cannula was inserted into the aorta and tied with the help of a ligature. A small nick was also made in the right auricle and blood was allowed to clear out of the system by injecting normal saline through the cannula. Following this, about $200 \mathrm{ml}$ of $10 \%$ formal saline was injected under 
low pressure with the help of a syringe till a clear solution started flowing out and the animal became pale and stiff. The perfused rats were kept in formalin for 3-4 days.

\section{Preparation of tissue for microscopy}

The liver was dissected out and cut into smaller pieces $(5 \mathrm{~mm})$. It was then washed in running tap water to remove surplus fixation. The tissue was dehydrated through changes in ascending grades of ethyl alcohol. Clearing of tissue was done in cedarwood oil followed by xylene $(15 \mathrm{~min})$ and then a mixture of xylene and paraffin wax in the ratio of 1:1 for half an hour. Tissue was further given three changes in paraffin wax (melting point $60^{\circ} \mathrm{C}$ ) for $1 \frac{1}{2}$ hour each and then embedded in wax. Blocks were prepared with the help of Leukart's "L"-shaped bars. The blocks were trimmed, labeled, and mounted on a block holder. Eight-micron-thick sections were cut using a rotatory microtome. The sections were picked up by floatation method on a glass slide smeared with egg albumin, glycerine, and thymol mixture. The slides were allowed to stand upright to drain and allow the sections to dry completely. They were then kept in the incubator at $37^{\circ} \mathrm{C}$ overnight to prevent displacement of sections during the staining process. The sections were later stained with hematoxylin and eosin.

For all linear measurements, Abercrombie's (1946) method was used in which ocular micrometer was calibrated by the standard stage micrometer and an image pro-express analyzer. Calibration of ocular micrometer was done with the help of stage micrometer for the high-power objective of a light microscope, keeping the particular eyepiece and particular objective, the readings were constant.

\section{Calculations}

\section{At 40x objective}

Each small division of the stage micrometer $=10 \mu \mathrm{m}$ 5 small divisions of ocular micrometer $=6$ small divisions of stage micrometer,

i.e. 5 small divisions of ocular micrometer $=60 \mu \mathrm{m}$

Therefore, 1 small division of ocular micrometer

$=60 / 5=12 \mu \mathrm{m}$

\section{Measurements}

The sizes of the hepatocytes with a clearly visible nucleolus were measured from four different fields of randomly selected sections of the liver. Two diameters at right angles to each other, passing through the center of each cell, were measured. One was considered the long diameter and the other was called the short diameter. The long and short diameters of the nucleus of the hepatocytes with a clearly visible nucleolus were measured. The readings from the two groups were tabu- lated and statistically analyzed. The central veins in the experimental and control animals were measured by recording the two diameters at right angles to each other. The sinusoids having a visible end at the central vein were studied. In each sinusoid, a long diameter and the maximum and minimum short diameters were recorded for both the groups.

Observations were made on randomly selected sections of the liver stained with hematoxylin and eosin on a Zeiss light microscope for both the groups.

This study was approved by Institutional Animal Ethics Committee (IAEC), UCMS, New Delhi on 10 March 2011. The IAEC approval number was IAEC/2011/46.

\section{RESULTS}

All the rats survived well during the period of the experiment, i.e. 14 days. No appreciable change was observed in their behavior, appetite, and motor activity during the experimental period. In the rats, the liver was situated in close contact with the diaphragm within the rib cage. It extended ventrally along the abdominal wall beyond the ribs. The diaphragmatic surface was convex and the visceral surface was in contact with the stomach, descending duodenum, transverse colon, jejunum, and spleen. The caudate process was related to the right kidney. The liver was dorsally related to the esophagus.

On histomorphometric examination, it was observed that the surface of liver was covered with a thin connective tissue capsule composed of abundance of collagen fibers which stained pink. From the capsule, very little interstitial connective tissue entered the parenchyma. Within these thin connective tissue septa, branches of the hepatic artery and hepatic portal vein together with the bile ducts were present, forming the portal tracts or portal triad [Figure 1]. One or more lymphatic vessels usually accompany this portal triad. The branches of the hepatic artery were lined by endothelium and surrounded by smooth muscle cells and fibers in the tunica media. The complex network of epithelial cells or hepatocytes, arranged in plates or one-cell-thick cords supported by connective tissue, constituted the liver parenchyma. The hepatic lobules appeared polygonal in shape, were bounded by loose connective tissue, and consisted of hepatic plates and sinusoids radiating around a central vein. The hepatocytes (parenchymal cells) appeared to be polyhedral in shape with a centrally placed rounded nucleus [Figure 1]. The cytoplasm of the hepatocytes appeared vacuolated and stained pink with eosin. Vacuolated appearance was probably due to the glycogen granules and the lipids, which were washed off during hematoxylin and eosin staining. The nucleus had a prominent nucleolus. Sinusoids at the periphery of the lobule were fused to form a reticulum, but they gradually achieved a radial arrangement toward the center. 
Attached on the endothelial surface of the sinusoidal lumen were the hepatic macrophages, known as the Kupffer cells. The Kupffer cells were irregular in shape and had flattened dark nucleus. During the experimental period of 14 days, it was observed that the rats became hypoactive after receiving ethephon for a few days. The decrease in activity was accompanied by decrease in food intake. On subsequent days, the animals appeared weak before administration of the drug, but became very aggressive and showed resistance while introducing the gavage tube for dosing. In the liver parenchyma, the one-cell-thick orderly arrangement of the hepatocytic plates appeared to be disrupted. The hepatocytes varied in size and were not so appropriately fitted together. In most places, the hepatocytes appeared shrunken with a small euchromatic nucleus. The cytoplasm stained dark pink with eosin and an increased cytoplasmic eosinophilia was seen. At places, the cytoplasm was darkly stained and highly eosinophilic with no vacuolation, which can be due to decreased glycogen content. The nuclei of the hepatocytes were smaller in size. Some hepatocytes were binucleated. The parenchyma showed areas of hepatocellular degeneration. Few of the hepatocytes appeared swollen and empty, with or without the lightly stained nucleus and indistinct cellular boundaries [Figure 2]. There were foci of inflammatory infiltrate (inf), i.e. macrophages and lymphocytes. On the other hand, a few hepatocytes appeared shrunken with a dark, highly eosinophilic cytoplasm and a pyknotic nucleus surrounded by a clear halo. These were predominantly seen in the periportal areas. Many small, structureless dying cells were seen in the space of Disse. The bile canaliculi between the hepatocytes throughout the liver appeared distended. The sinusoids (sn), the central vein (cv), and the hepatic vein appeared dilated.

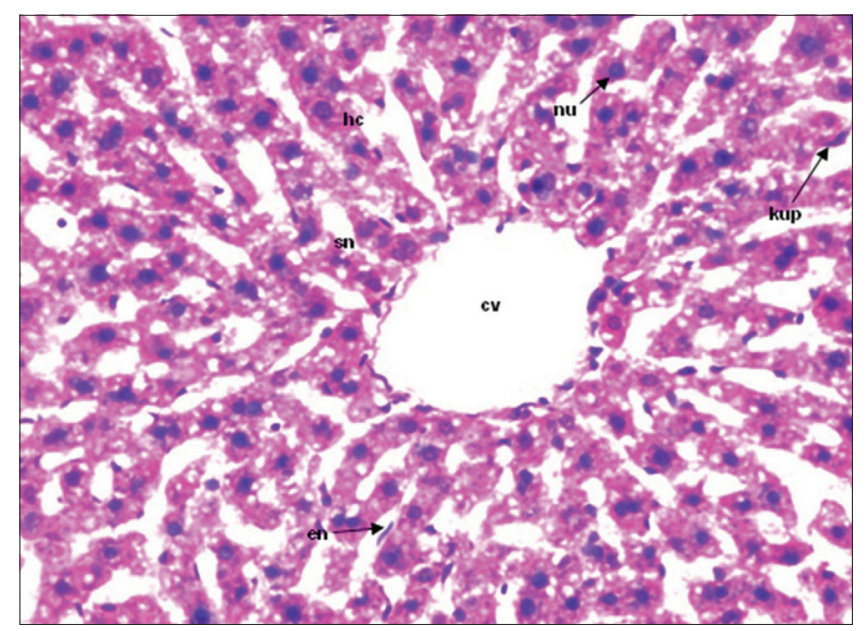

Figure 1: Photomicrograph of a transverse section of the liver in the control rat showing the central vein (cv), lined by the endothelium (en) and surrounded by the radiating cords of hepatocytes (hc) and sinusoids (sn). The Kupffer cells (Kup) are attached to the endothelium of sinusoids. (Hematoxylin and eosin, 200×).

\section{DISCUSSION}

The weight of the liver is $4.15 \%$ of the total body weight. ${ }^{[21,22]}$ Liver is the main target of toxicity of several compounds because most of the substances undergo first-pass metabolism here. Therefore, it becomes an organ of extreme importance for studying the effects of various chemicals administered into the body. El-Okazy studied the effects of plant growth regulators, gibberellic acid and ethephon, on mice and demonstrated a dose-dependent decrease in aspartate aminotransferase (AST) in groups treated with the combination of gibberellic acid and ethephon. ${ }^{[23]}$ AST is considered as a specific indicator of liver function and/ or damage. The histomorphological and histomorphometric studies of the liver were not conducted.

In the present study, the rats became very active and irritable at the time of introducing the gavage tube for dosing. This was accompanied by a decrease in the motor activity and vocalization. After administering ethephon by oral gavage at a single dose of 500,1000 , or $2000 \mathrm{mg} / \mathrm{kg}$ body weight, Beyrouty observed a decrease in the motor activity and vocalization, in addition to abnormal respiration, breathing, ptosis, lacrimation, piloerection, abnormal tone, and altered visual placing within $8 \mathrm{~h}$ of dosing. Observations of our study are in accordance with this study. ${ }^{[24]}$

The histomorphological and histomorphometric study of the control groups revealed a normal microanatomy of the liver. Connective tissue septa from the capsule extended deep into the parenchyma surrounding the hepatic lobules and at sites contained the branches of the hepatic artery,

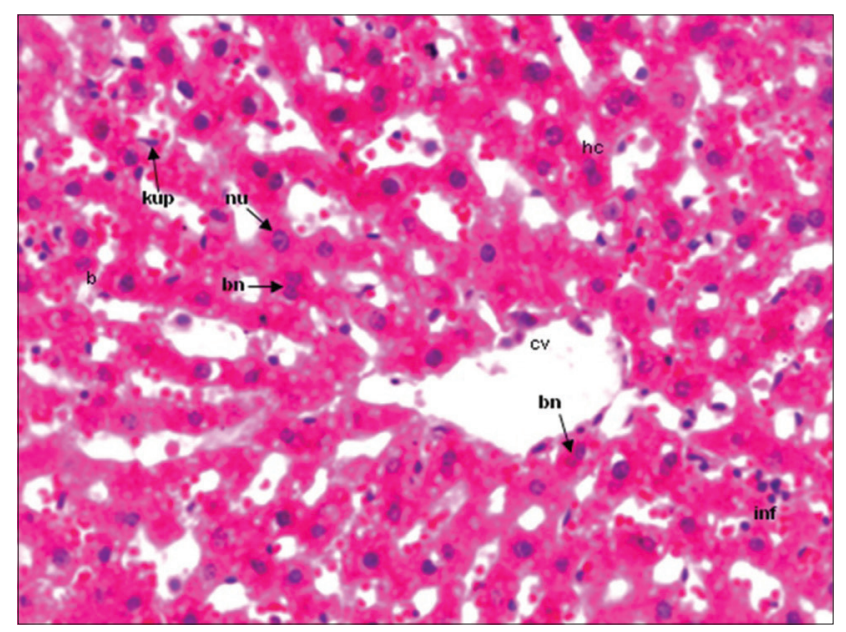

Figure 2: Photomicrograph of a transverse section of the liver of an experimental rat showing the central vein $(\mathrm{cv})$. The size of hepatocytes (hc) and nucleus (nu) appears to be reduced with increased cytoplasmic eosinophilia and decreased basophilia, respectively. The normal laminar pattern of the hepatocytes is disheveled and a number of binucleated cells (bn) are seen. The sinusoids appear to be filled with RBCs and inflammatory cells (inf). (Hematoxylin and eosin, 200×). 
hepatic portal vein, and bile ductules forming the portal tracts or portal triad. The epithelial cells or hepatocytes formed a complex network forming the liver parenchyma and were arranged in plates or one-cell-thick cords supported by connective tissue [Figure 3]. The hepatocytes appeared polyhedral in shape with a centrally placed, rounded, euchromatic nucleus and a prominent nucleolus [Figure 1]. In the control rats, the hepatocytes had a mean long and short diameter of $16.5 \pm 3.59$ and $13.9 \pm 3.59 \mu \mathrm{m}$, respectively. The mean long and short diameters of nucleus were found to be $6.15 \pm 1.72$ and $6.05 \pm 1.68 \mu \mathrm{m}$, respectively. The central veins had a mean long and short diameter of $65.75 \pm 24.83$ and $45.7 \pm 14.69 \mu \mathrm{m}$, respectively. The sinusoids had a mean long diameter of $39.75 \pm 16.94 \mu \mathrm{m}$, and a mean maximum and a mean minimum short diameter of $8.75 \pm 3.13$ and $3.98 \pm 1.72 \mu \mathrm{m}$, respectively [Table 1]. These findings are in accordance with the findings of Gershbein and Elias. ${ }^{[25]}$

In the experimental rats, the one-cell-thick, orderly arrangement of the hepatocytic cords of the liver was disrupted and the hepatocytes appeared to be singly placed probably due to the co-existing immense dilatation of the bile canaliculi in between the hepatocytes [Figure 2]. The hepatocytes varied in size. Most of the hepatocytes appeared to be decreased in their size and when histomicrometry was done, these cells had a mean long and short diameter of $15.02 \pm 4.20$ and $12.08 \pm 3.012 \mu \mathrm{m}$, respectively. When compared to the control group, they were statistically significantly decreased.

The nucleus appeared to be euchromatic and small, with prominent nucleoli. The mean long and short diameters of the nucleus of the hepatocytes were found to be $5.08 \pm 1.93$ and $5.08 \pm 1.93 \mu \mathrm{m}$, respectively. The decrease in the size of the nucleus was statistically significant as compared to that of the control animals. It is well known that the size of the nucleus is an indicator of the functional activity of the cell.

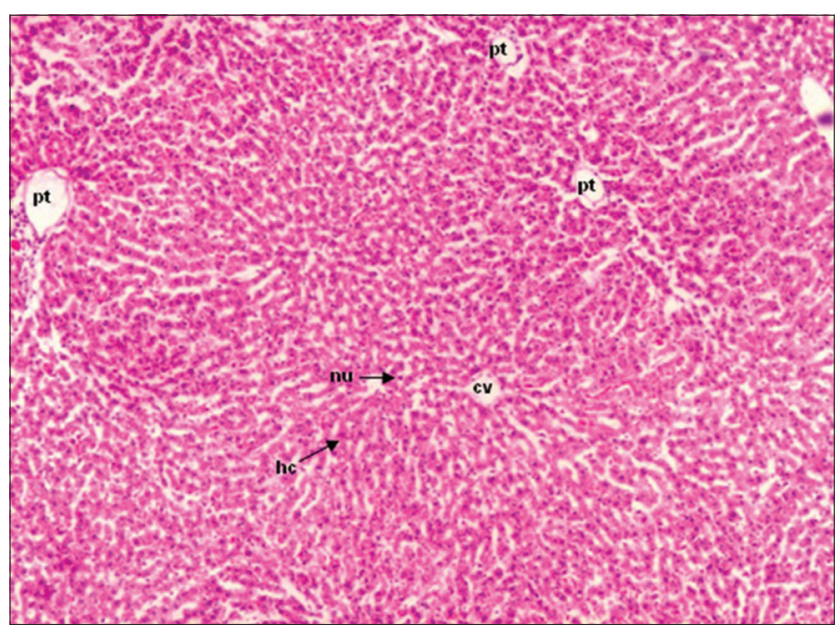

Figure 3: Photomicrograph of a transverse section of the liver in the control rat showing the portal triads (pt), hepatocytes (hc), nucleus (nu), and central vein (cv). (Hematoxylin and eosin, 40×).
Therefore, the observed decrease in the size of the nucleus suggests that these cells are probably hypoactive. Some of the hepatocytes appeared to have a pyknotic, heterochromatic nucleus, suggestive of degenerative changes. These findings were consistent with those of Hussein et al. who found mild piece-meal necrosis of hepatocytes on histopathological examination of liver in rats after administering a plant growth regulator, gibberellic acid. ${ }^{[26]}$ In addition, they observed that the cytoplasm of the hepatocytes appeared eosinophilic with almost no visible vacuolations and an apparently normal basophilic nucleus. Most of the hepatocytes appeared apoptotic and shrunken, having a pyknotic nucleus [Figure 2].

Some of the degenerating cells became too shrunken and appeared like small, structureless, hyaline masses in the space of Disse [Figure 2]. These findings are suggestive of hepatocellular degeneration and were consistent with the findings of Altin et al. who administered 4-chlorophenoxy acetic acid (4-CPA), a plant growth regulator, to rats and reported hepatocellular necrosis after a high dose. ${ }^{[27]}$

The sinusoids had a mean long diameter of $39.75 \pm 16.943 \mu \mathrm{m}$, and mean maximum and mean minimum short diameters of $8.75 \pm 3.128$ and $3.975 \pm 1.722 \mu \mathrm{m}$, respectively. There was a statistically significant increase in the diameter of the sinusoids as compared to that of the control group. The central veins had a mean long diameter of $65.75 \pm 24.826 \mu \mathrm{m}$ and a mean short diameter of $45.7 \pm 14.686 \mu \mathrm{m}$. There was a statistically significant increase in the diameter of the central vein of the experimental rats as compared to that of the control group. At most sites, the portal vein appeared to be dilated. At places, there were areas of hemorrhage where the normal parenchyma was replaced by large blood-filled spaces and the neighboring sinusoids were hugely distended with hemorrhagic fluid [Figure 4].

Table 1: Comparison of groups for histomorphometric parameters

\begin{tabular}{|c|c|c|c|}
\hline \multirow[t]{2}{*}{ Parameters } & \multicolumn{2}{|c|}{ Mean \pm SD } & \multirow{2}{*}{$\begin{array}{c}p \\
\text { (student's } \\
\text { " } t \text { " test) }\end{array}$} \\
\hline & Experimental & Control & \\
\hline Long diameter of hepatocytes & $15.02 \pm 4.20$ & $16.5 \pm 3.59$ & 0.008 \\
\hline Short diameter of hepatocytes & $12.08 \pm 3.02$ & $13.9 \pm 3.59$ & $<0.0001$ \\
\hline $\begin{array}{l}\text { Long diameter of nucleus } \\
\text { of hepatocytes }\end{array}$ & $5.08 \pm 1.93$ & $6.15 \pm 1.72$ & $<0.0001$ \\
\hline $\begin{array}{l}\text { Short diameter of nucleus } \\
\text { of hepatocytes }\end{array}$ & $5.08 \pm 1.93$ & $6.05 \pm 1.68$ & $<0.0001$ \\
\hline Long diameter of central vein & $75.72 \pm 33.53$ & $65.75 \pm 24.83$ & 0.018 \\
\hline Short diameter of central vein & $48.35 \pm 17.58$ & $45.7 \pm 14.69$ & 0.249 \\
\hline Long diameter of sinusoids & $46.3 \pm 23.36$ & $39.75 \pm 16.94$ & 0.024 \\
\hline $\begin{array}{l}\text { Short diameter (maximum) } \\
\text { of sinusoids }\end{array}$ & $12.2 \pm 5.23$ & $8.75 \pm 3.13$ & $<0.0001$ \\
\hline $\begin{array}{l}\text { Short diameter (minimum) } \\
\text { of sinusoids }\end{array}$ & $5.90 \pm 2.70$ & $3.98 \pm 1.72$ & $<0.0001$ \\
\hline
\end{tabular}

Abbreviation: SD: Standard deviation 


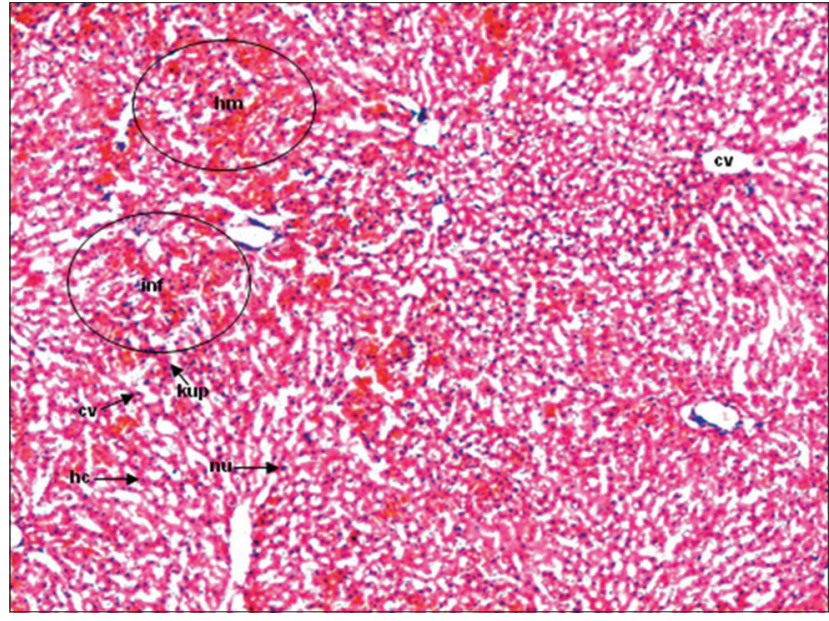

Figure 4: Photomicrograph of a transverse section of the liver in the experimental rat showing the central vein $(\mathrm{cv})$. The normal microanatomy of the liver appears to be disrupted with massive hemorrhage (hm) and disrupted hepatocytic (hc) cords. Areas of inflammatory infiltrations (inf) and Kupffer cells (kup) are seen. (Hematoxylin and eosin, 40×).

\section{Limitations of this study}

We gave a fixed dose of ethephon and sacrificed rats on a fixed day (i.e. $14^{\text {th }}$ day), so we could not comment on the dose- and duration-dependent changes in the liver. Due to financial constraints, we had not included serial measurements of liver enzymes in our study. However, this could have been useful, as then we could have correlated derangements in enzymes with pathological changes. Dose- and duration-dependent changes in liver enzymes could also be useful information.

\section{Conclusion}

In the present study, the histomorphometric changes in the liver of ethephon-treated rats were markedly different from those of the control rats. The disheveled pattern of the one-cell-thick orderly arrangement of hepatocytic cords, pathological features suggesting decreased cellular metabolism, the presence of structureless hyaline masses, inflammatory infiltrate, decreased cytoplasmic vacuolation, along with the dilatation of the blood vessels and the bile canaliculi are suggestive of toxic hepatitis probably induced by the ethephon. In the present study, the observations in the liver are probably indicative of inflammatory and degenerative changes which are suggestive of toxic hepatitis after administration of ethephon in albino rats. We suggest that further studies are required to explore pharmacodynamics, explaining the exact mechanism of hepatotoxicity of ethephon.

\section{Financial support and sponsorship}

\section{Nil.}

\section{Conflicts of interest}

There are no conflicts of interest.

\section{REFERENCES}

1. US Environmental Protection Agency. Gibberellic acid Tolerence Exemption 10/98, Federal Register 1998;63:56882-6. Available from: http://pmep.cce.cornell.edu/profiles/herb-growthreg/ fatty-alcohol-monuron/gibberellic-acid/Gibberellins tol exp 1098. html. [Last accessed on 2014 May 10].

2. Moore TC. Ethylene: Biochemistry and Physiology of Plant Hormones, $2^{\text {nd }}$ ed. New York- Heidelberg-Berlin; Springer-Verlag; 1989. p. 228-59.

3. Weed Science Society of America. Herbicide Handbook, $6^{\text {th }}$ ed.; Weed Science Society of America: Champaign, Illinois 1989. p. $220-1$.

4. Abeles FB, Morgan PW, Saltveit ME Jr. Ethylene in Plant Biology, $2^{\text {nd }}$ ed. New York: Academic Press Inc.; 1992. p. 414.

5. Silpi U, Chantuma P, Kosaisawe J, Thanisawanyangkura S, Gohet E. In: Sainte-Beuve Jérôme (ed). Biotechnology and Rubber Tree: Proceedings of IRRDB Symposium, Montpellier, France, 25-28 September, 2001.

6. Rodwell DE, Spencer AG, Allen S Teratology study in rats: IRDC No. 369-042. Prepared by International Research and Development Corp, 1980. p. 264-7.

7. Ferrell J. 104-week chronic administration of ethrel in male and female rats. Final Pathology Report: Project No. 141-263 (HLA) 1984. p. 747.

8. Van Miller J. Lifetime dietary combined chronic toxicity and oncogenicity study with ethephon in albino rats: Laboratory Project ID: 51-501. prepared by Union Carbide, Bushy Run Research Centre, for Rhone Poulenc1989. p. 2427.

9. Henwood S. Teratology study with ethephon technical-base 250 in rats: Project ID HLA 6224-125. Prepared by Hazleton Laboratories America, Inc. 1989. p. 286.

10. Klonne D. Supplemental Historical Control Data Requested for the lifetime dietary Oncogenicity study with ethephon in Albino Mice: Study \#51-502, November 14, 1988, Bushy Run Research Center prepared by Rhone Poulenc Ag Co. 1994. p. 17.

11. Yazar S, Baydan E. The subchronic toxic effects of plant growth promoters in mice. Ankara Univ Vet Fak Derg 2008;55:17-21.

12. Cetinkaya MA, Baydan E. Investigation of in vitro effects of ethephon and chlorpyrifos, either alone or in combination, on rat intestinal muscle contraction. Interdiscip Toxicol 2010;3:35-9.

13. Henwood S. Three week dermal toxicity study with ethephon (technical) in rabbits: Lab project no.- HLA/6224/141. Prepared by prepared by Hazleton Laboratories America, Inc; 1989. p. 247.

14. Hamada N. One-year oral toxicity study in beagle dogs with ethephon: Final Report: HLA Study No. 400-722. Prepared by Hazleton Laboratories America, Inc., Sponsor Rhone Poulenc Ag Co.; 1989. p. 557.

15. Weatherholtz W. Two year dietary study in dogs: Ethrel addendum to final project No. 141-260. Prepared by Hazleton Laboratories America, Inc., 1984. p. 5. 
16. El Raouf AA, Girgis SM. Mutagenic, teratogenic and biochemical effects of ethephon on pregnant mice and their fetuses. Glob Vet 2011;6:251-7.

17. Weatherholtz WM, Misretta LH, Wilfe GM. Teratology study in Rabbits: Technical Ethephon: Project No. 400-635. Final rept. prepared by Hazleton Laboratories America, Inc., submitted by Union Carbide Agricultural Products Co., Inc., Ambler, Pa.; CDL: 246064-B) 1981.

18. Theiss JC, Shimkin MB. Effect of the plant growth regulator, 2-chloroethylphophonic acid, on spontaneous and chemically-induced lung tumorigenesis in strain A mice. Food Cosmet Toxicol $1980 ; 18: 129-32$.

19. International Programme on Chemical Safety (Inchem) (2002): Pesticide Residues in food-2002- Joint FAO/WHO meeting on Pesticide Residues. Ethephon. Available from: [http://www.inchem. org/documents/jmpr/jmpmono/2002pr05.htm]. [Last assessed on 2014 Jul 25].

20. Beyrouty P. An acute study of the potential effects of a single orally administered dose of ethephon, technical grade, on behavior and neuromorphology in rats. Unpublished report BRL Project ID 97412, Bio-Research Laboratories Ltd, Senneville, Quebec, Canada. Submitted to WHO by Aventis CropScience SA, Secteur Agro, Lyon, France; 1996b.

21. Caster WO, Poncelet J, Simon AB, Armstrong WD. Tissue weights of the rat. I. Normal values determined by dissection and chemical methods. Proc Soc Exp Biol Med 1956;91:122-6.

22. Webster SH, Lilijegren EJ, Zimmer DJ. Organ; body weight ratios for liver, kidneys and spleen of laboratory animals; albino rat. Am J Anat 1947;81:477-513.

23. El-Okazy AM. The effects of combination of Gibberellic acid -3(GA3) and ethephon (2 Chloroethyl Phosphonic Acid) (Plant Growth Regulators) on same physiological parameters in Mice. J Egypt Public Health Assoc 2008;83:67-86.

24. Beyrouty P. A time of peak effects study of a single orally administered dose of ethephon in rats. Unpublished report BRL Project ID 97411, Bio-Research Laboratories Ltd, Senneville, Quebec, Canada. Submitted to WHO by Aventis CropScience SA, Secteur Agro, Lyon, France; 1996.

25. Gershbein LL, Elias H. Observations on the anatomy on the rat liver. Anat Rec 1954;120:85-98.

26. Hussein WF, Farahat FY, Abass MA, Shehata AS. Hepatotoxic potential of Gibberellic Acid (GA3) in adult male albino rats. Life Sci J 2011;8:373-83.

27. Altin DT, Ozer C, Yesilkaya E, Babül A, Bideci A, Cinaz P. Effect of the plant growth regulator (4-Chlorophenoxy acetic acid) into the oxıdatıve stress parameters in rat liver. Afr J Pharm Pharmacol 2011;5:2498-504.

This is an open access article distributed under the terms of the Creative Commons Attribution-NonCommercial-ShareAlike 3.0 License, which allows others to remix, tweak, and build upon the work non-commercially, as long as the author is credited and the new creations are licensed under the identical terms.

For reprints contact: reprints@medknow.com 